\title{
DE LO "GOYESCO" MEXICANO
}

A PUNTES DE UN EXTRANJERO

$\mathbf{P} \mathbf{Q} \mathbf{R}$

JUAN DE LA ENCINA

UNAS leves palabras más, pronunciadas hace:meses en el Paraninfo de la Universidad Autónoma de México y recogidas luego sin ninguna enmienda en mi libro El Mundo histórico y poético de Goya, han causado cierta extrafieza a algunos de los doctos amigos que redactan estos Anales. Decta yo en aquella ocasión que, al poner pie en tierra mexicana, habia recibido de ella una fuerte impresión de "espíritu goyesco", y que precisamente esta irnpresión y este espíritu que yo adverti, me llevaron a disertar sobre el arte de Goya, rechazando por el momento otros temas de estética general que yo traia preparados.

Pero.. ce posible $\rightarrow$ te decían esos buerios amigos- que vea usted el panoramá mexicano teñido de colores "goyescos"? ¿ $\mathrm{No}$ sufrira, amigo, alguna manera de espejismo? Explique y aclare su insinuación, porque ès probable que no vayamos de acuerdo. Esta cortés petición hubo de alarmarnie. un poco. ¿Me habré dejado llevar -me decia a mi mismo- de mi hábito y propensión inveterada de intuír las cosas de una manera impresionista? Porque los hombres que me insinuaban reparos san grandes conocedores de su pais y de sn historia, ameritados investigadores en materia de arte y estética. 
Me di, pues, a pensar en mi observación, que al comienzo no fué otra cosa que mera impresión artística nacida del entusiasmo - en ocasiones llegó a embriaguez- que producía en una naturaleza sensible la para mí nueva -iy tánto! - belleza mexicana. Luego, y acompañado de esta preocupación, viajé un poco. $\mathrm{Y}$ esos viajes, he de decirlo, no hicieron sino acrecentar y corroborar el sentido de mis primeras impresiones.

En resolución, amigos, que sigo en mis trece, esto es, que este México me sigue pareciendo una gran cantera de "espíritu goyesco". Correspondiendo a la gentileza del Director de los Anales, que me ofrece sus páginas para ello, me explicaré brevemente, aunque el tema acaso exija amplios desarrollos.

Claro está que no es menester advertir que, al sentar esta afirmación, pretenda yo hallar una semejanza o parecido concreto, real y material entre lo que pudiera llamarse "el mundo de Goya" y el ambiente y arte mexicanos. Aunque un observador, que conociera la obra de Goya, no necesitaría —ciertamente- concentrar mucho su atención para descubrir en ciertos tipos y en ciertas costumbres mexicanos, rasgos concretos y vivos equivalentes, cuando no iguales, a los que caracterizan el mundo de Goya. Al hablar de lo "goyesco mexicano", no me refiero yo particularmente a ellos, sino a ciertos valores estéticos generales que pudieran recibir este calificativo: goyesco, que para los españoles entendidos en arte, y creo que también para los mexicanos, posée un sentido claro, preciso, inequívoco.

Líbrenme, sin embargo, los dioses benignos del Anáhuac de incurrir en la excesiva pretensión de hacer de lo goyesco una categoría estética de amplia base. Líbrenme de hacer con semejante término lo que los alemanes hicieron con el barroco y otros vocablos técnicos del arte, que, de términos de restringida significación artística, los extendieron a significar nada menos que formas y ciclos generales de la cultura. Así, hoy tenemos una filosofía, una mistica, una literatura, una matemática, un yo no sé qué, barroco, plateresco, churrigueresco, románico, gótico, etc., etc. Esta transposición y ampliación de términos, a veces posée la ventaja de que, por el sólo hecho de su empleo más o menos metafórico, ilumina quizá las cosas con nueva luz, de modo que un Quevedo -v. g.- barroco, por el sólo hecho de aplicarle este calificativo, parece otra cosa que un Quevedo conceptista, desgarrado, sombrío, agrio, etc., etc. Bien como si a un rostro que habíamos visto siempre iluminado con luz blanca, lo viéramos de pronto esclarecido por una luz roja.

No, no pretendo tanto, ni mucho menos. Lo goyesco es para mí meramente una variante o matiz particular de ciertas categorías estéticas. Toma 
su sabor, por decirlo así, de tres categorías principales: la de la gracia, la de lo dramático y la de grotesco o feo artístico. Fundidas entre sí, en ciertas dosis, si así puede hablarse, dan un resultado estético que se llama lo goyesco. No creo que se pueda definir con mucho más rigor. Soy de los que creen que las cosas de arte admiten de un modo harto limitado las definiciones "more geometrico". Sin embargo, aunque las definiciones de ese tipo no puedan siempre establecerse o sustentarse, la cosa suele estar ahí presente, con vida y carácter inequívocos, y hablan al espíritu con entera claridad, con penetrante fuerza - fuerza y claridad que, si bien se mira, no suelen poseer las definiciones escolásticas, ni mucho menos-. Para mayor claridad, añadiría yo a esa categoría de lo goyesco otra de suma importancia, como que es la base de sustentación de la obra artística: la vida.

Lo goyesco está, pues, dotado de una vida intensísima, bullente, de puro instinto. Un como chorro de surtidor enérgico de vida espontánea y primigenia. Como Goya mismo, que nada tenía de intelectual, a pesar de que su "visión" se parecía a veces no poco a la de Quevedo, la vida de lo goyesco, conviene repetirlo, es vida espontánea, de primer brote, riquísima en jugos, a modo de invención de la naturaleza en horas de plenitud.

Pues bien: el conjunto de todas estas virtudes estéticas lo hallo yo como abundantemente desparramado por los ámbitos de México, y eso es lo que llamo "lo goyesco mexicano". Porque, mirado desde un punto de vista puramente estético, a mí me parece México un pueblo todo lleno de gracia y de carácter, un pueblo - además-dramático, y un pueblo, en fin, que, como el español y las brujas de Macbeth, proclama resueltamente y sin remilgos "la hermosura de lo feo". No me lo tomen a mal, si mis razones no les convencen, porque me precio de fervor por la belleza mexicana, pero debo confesar que ha sido en México donde he llegado a comprender más y mejor aquel concepto que ululaban las brujas "shakespearianas" en el páramo, mientras volvían el seso a Macbeth: "lo feo es lo hermoso"... y eso que en España sabemos no poco de esa clase de equívocos conceptos estéticos. Un mexicano ilustre, mi amigo don Alfonso Reyes, en sus Cartones de Madrid, pudo perfectamente atestiguarlo. El agudo y fino escritor de Monterrey es en esta obra... y en otras suyas también, por mexicano, un cultivador del espíritu goyesco. "Lo feo es lo hermoso". He aquí un principio estético muy español... ¿ $Y$ por qué no ha de serlo también mexicano, pues tantos testimonios pueden hallarse en esta maravillosa tierra a su favor? Yo no creo, en modo alguno, que Quevedo - si mal no recuerdo, fué mi amigo Pedro Salinas quien lo dijo en Bellas Artes- haya sido el primero en realizar en las 
letras españolas la estética de lo feo. No, no lo creo. Porque los españoles hemos cultivado en todo tiempo en arte la paradoja estética de la hermosura de lo feo. Somos indudablemente especialistas en el ramo. De ahí que lo feo goyesco, no sólo tenga un antecedente egregio en lo feo quevedesco, sino que viene de mucho más lejos: por lo menos de nuestra Edad Media.

En España podría levantarse con cierta precisión y riqueza el plano de lo que Rosenkranz llamó "el infierno estético" (Aestetik des Haesslichen, I, 857, Estética de lo Feo), es decir, lo contrario de aquel concepto de la belleza eterna y quieta que la forastera de Mantinea proclamó ante Sócrates embebecido de sublimidad. El señor de ese infierno, como el del otro, es Satán. En Satán, pues, se simboliza o encarna la "idea", dechado, arquetipo y ejemplo supremo y permanente de lo feo.

Pues bien: en el sentido expresado, los artistas españoles propenden a lo satánico (en lo moderno, basta citar a Valle Inclán, Solana, Zuloaga y al mismo Picasso) ... y los mexicanos también. Ni más ni menos. Todo lo que yo conozco del sentido y gusto estético mexicano, anterior o posterior a Cortés, se va en parte muy considerable por esa turbadora y mágica pendiente. En el Museo Nacional tienen todos los ejemplos que quieran para lo precortesiano. $\mathrm{Y}$ para lo moderno... no hay sino dirigirse a Diego Rivera, a Clemente Orozco, a Goitia, a Siqueiros, etc., etc. Lo que sobran son ejemplos con qué argumentar. $\mathrm{Y}$ de paso les diré una cosa, que a los que se la he dicho antes ha parecido un tanto arbitraria, yo creo que no lo es: el arte mexicano moderno, muy propio para despertar la pasión crítica de quien sepa mirar y ver, tiene, a mi juicio, no pocas relaciones interiores y exteriores con el arte aborigen que puede verse en el apasionante Museo Nacional. Entre uno y otro, aunque haya tan enormes diferencias - yo no puedo negarlas-, la solución de continuidad establecida por la conquista no es tan grande como pudiera, a primera vista, suponerse. Pero dejemos esto, que algún día he de tratarlo con extensión.

Este rasgo o carácter que acabo de señalar, ¿no es, pues, un rasgo o carácter auténticamente goyesco? Y con el abismo de lo feo coexiste el abismo de la pasión. ¿Quién pudiera imaginarse lo goyesco sin un fondo pasional? Porque si suprimimos este ingrediente, la pasión, lo goyesco se nos evapora o pierde por lo menos su realce y energía.

De lo dramático mexicano... no hay por qué hablar. Salta a la vista de quien considera la vida y el arte de México. Su vida histórica, ¿qué es si no 
una especie de huracán dramático, ni más ni menos que la vida española - ia que hubo de transcribir, en parte, en sus pinturas Goya?

Y de la gracia mexicana... ¿qué quieren que les diga ? La siento yo circular por todas partes: en la calle, en el hogar, por la habla popular y la culta ("el pelao", tan bien descrito por Samuel Ramos, ¿qué es si no un tipo enteramente goyesco?), etc., etc. Por todas partes yo la siento que va derramando su sal $\rightarrow$ y precisamente por la calidad de esa sal, por su mordente, por su frescura y garbo, por su brio y su arrojo valiente-, a pesar de ciertas languideces que acaso me atrevería a llamar tropicales, la considero que entra de lleno en el concepto de la gracia goyesca.

Estas son, pues, queridos amigos, algunas de las razones con las que yo trato de justificar mi aserto. Si no les convencieran, y fuera necesario alegar otras o desarrollar más las expuestas, siempre me tienen dispuesto a ello con la mayor simpatía y cordialidad hacia ustedes. 


\section{Chetl, Crawford O'Gorman}

El Instituto de Investigaciones Estéticas se propone dar a conocer, por medio de sus Anales, ha que los artistas más destacados de México piensan acerca de su arte. Poro la generalided del público estudioso no es facil comocer las ideas estéticas de cada de ellos y por eso se ha pensado que seria titil recoger las reflexiones en que cada uno fija su posición frente a la actividad que desarrolla. Damos ahora la primera de esas confesiones, en el idioma en que fué escrita para evitar los escollos de una traducción, y en números subsecuentes continkaremos esta serie que se nos antoja llena de interés.

Cecil Crauford O'Gorman no necesita presentación. Irlandés de origen, reside en México desde hace uros cuarenta años y es aqui donde ha realizado su interesante y varia producción pictórica. Ha crueado la vida entre los movimientos artíticos del siglo, siempre atento a las nuevas corrientes, que ha experimentado por cuenta propia, $y$ se encuentra en la actualidad rico en conocimientos $y$ dueño de un equilibrio distinguido, que nunca perdió. Su sentido crítico presta mucho interés a su confesión estética, la cual, sumada a otras, nos ayudará a valorar el panorama ideológico de nuestros artistas contemporáneos. 